\title{
A survival analysis of South African children under the age of five years
}

Author:
Zeleke Worku'
Affiliation:
'School of Business, Tshwane
University of Technology,
South Africa
Correspondence to:
Zeleke Worku
Email:
workuz@tut.ac.za
Postal address:
PO Box 11333 , The
Tramshed, Pretoria 0126,
South Africa
Dates:
Received: 30 June 2009
Accepted: 21 Feb. 2011
Published: 26 Aug. 2011
How to cite this article:
Worku, Z., 2011, 'A survival
analysis of South African
children under the age of five
years', Health SA Gesondheid
16(1), Art. \#472, 12 pages.
doi:10.4102/hsag.v16i1.472

C 2011. The Authors. Licensee: AOSIS OpenJournals. This work is licensed under the Creative Commons Attribution License.
The South African Demographic Health Survey data set (SADHS) of 2003 contains massive individual-level information on South African children under the age of five years selected from a random sample of 7756 households. The data set contains data on socio-economic, demographic, health-related and sanitary variables gathered by using multistage cluster sampling. The objective of the study was to identify key predictors of mortality amongst children under the age of five years. Logistic regression analysis and Cox regression were used for data analysis.

Under-five mortality was significantly influenced by three predictor variables (breastfeeding, marital status, and ownership of a flush toilet). The hazard ratio of the variable 'breastfeeding' was 3.09 with $P=0.000$ and $95 \%$ confidence interval (CI) of $(1.899,5.033)$. The hazard ratio of the variable 'toilet' was 2.35 with $P=0.016$ and $95 \%$ confidence interval of $(1.172,4.707)$. The hazard ratio of the variable 'marital status' was 1.74 with $P=0.035$ and $95 \%$ confidence interval of $(1.041,2.912)$. Adjustment was factored in for the mother's level of education and wealth index.

Die Suid-Afrikaanse Demografiese en Gesondheidsopname-datastel (The South African Demographic Health Survey data set [SADHS]) van 2003 bevat 'n enorme hoeveelheid individuele-vlak inligting rakende kinders onder vyf jaar uit 7756 huishoudings in Suid-Afrika. Die datastel bevat inligting rakende sosio-ekonomiese, demografiese, en gesondheidsverwante veranderlikes, en sanitêre-veranderlikes, is versamel deur gebruik te maak van multistadiatrosanalise. Die oogmerk met die studie was die identifisering van sleutelpredikatore ten opsigte van sterftes van kinders onder die ouderdom van vyf jaar. Logistieke-opnameregressie analise en Cox-regressie is gebruik om die data te analiseer.

Onder vyf-sterftes word beduidend beïnvloed deur drie predikatorveranderlikes (duurte van borsvoeding, huwelikstatus en toegang tot ' $n$ spoeltoilet). Die risikoverhouding van die borsvoeding-veranderlike was 3.09 met $P=0.000$ en 'n $95 \%$ sekerheidsinterval van $(1.899$, 5.033). Die risikoverhouding van die toiletveranderlike was 2.35 met $P=0.006$ en $95 \%$ sekerheidsinterval van (1.172, 4.707). Die risikoverhouding van die huwelikstatus-veranderlike was 1.74 met $P=0.035$ en $95 \%$ sekerheidsinterval van $(1.041,2.912)$. Aanpassings is gemaak vir die opvoedingsvlak van die moeder asook die welgesteldheidsindeks.

\section{Introduction}

\section{Problem statement}

In most parts of Africa including South Africa, the outcomes of pregnancies and the survival of new-borns are influenced by access to basic health services and the quality of socio-economic services that are made available to the population. Rural mothers and children are often disadvantaged in terms of access to basic health services. The United Nations Children's Fund (UNICEF), (2009:2-7) has reported that lack of access to basic health services is a key indicator of maternal and child mortality and morbidity in South Africa and in most sub-Saharan African countries. Institutions such as Stand Against Poverty (2009:1-12) argue that addressing poverty amongst mothers and children is essential for reducing child mortality and morbidity in subSaharan African countries such as South Africa. According to the United Nations Development Programme (UNDP), (2009:1-21) sub-Saharan African countries with high child mortality rates are characterised by low human-development indices and the allocation of inadequate resources for the provision of basic services such as health and education. The UNDP monitors the achievement made towards the Millennium Development Goals by sub-Saharan African countries, such as South Africa, based on performance-monitoring indicators. The South African Demographic and Health Survey (SADHS) is a typical survey designed for obtaining data on key 
indicators used by institutions such as the UNDP. As such, the data set is strategically valuable and is used for informing planning and policy making. The most recent SADHS was conducted in 2003, but the data set was made available to the general public only late in 2007. The data set contains data on maternal and child health, primary health care, basic health services, HIV (Human immunodeficiency virus) and AIDS (Acquired immune deficiency syndrome), the use of family planning methods and contraceptives, sanitation, and environmental health. The survey was conducted in 7756 households. This study aims to identify key socio-economic predictors of mortality amongst children under the age of five years with a view to draw attention to the plight of children and mothers who need assistance from the South African government.

The under-five mortality rate is the probability that a child dies before reaching the age of five years, and is expressed as a rate per 1000 live births. The figure is a key indicator used for the allocation of resources and for measuring the level of development of countries in Africa and elsewhere. Poor countries often have high under-five mortality rates, whereas rich countries have low rates. In most developing countries, the rate is 88 per 1000 live births. In the world's poorest countries, the rate is roughly 120 per 1000 live births. According to the 2003-SADHS, the under-five mortality rate of South Africa is 58 per 1000 live births (South African National Department of Health 2008).

In most sub-Saharan African countries, studies have shown that the mortality of children younger than five years is often influenced by socio-economic factors and related illnesses (Union for African Population Studies 2009:3). In South Africa, five diseases (i.e. pneumonia, diarrhoea, malaria, measles, and HIV and AIDS) account for more than $50 \%$ of all deaths in children younger than five. Malnutrition increases the risk of dying from these diseases and contributes to more than half of all deaths amongst children under the age of five years. This identifies malnutrition as the most common cause of death of the mother and foetus, and can result in babies with low birth weight. It has been established that poverty results in under-nutrition (UNICEF 2009:1-6).

Planners and policy makers in South Africa argue that the current rate of 58 deaths per 1000 live births could be reduced by improving access to basic health services, especially with regard to rural mothers and their children (South African National Department of Health 2008:1-11). The general assertion is that this figure is unacceptably high for South Africa. There is a myriad of socio-economic factors that affect such a high mortality rate. The main objective of this analysis was to determine socio-economic factors that affect mortality amongst under-five children in South Africa. The study is based on a secondary data analysis of the SADHS of 2003. The survey consisted of a multistage cluster sample of 2221 children who were born in the five years before the survey, when a similar survey was conducted in 1998.

Results obtained from this analysis show that factors such as the practice of exclusive breastfeeding, access to a flush toilet, the mother's level of education, the age of the mother, and the residential area influence the survival of children. These results show that rural children are disadvantaged in comparison with urban children with regard to access to clean water, immunisation, and access to a flush toilet, education, infrastructure, and so forth.

\section{Rationale of the study}

The rationale behind the study is that the SADHS provides a valuable data set that has been released recently and has not been fully analysed yet. Furthermore, socio-economic causes of mortality amongst infants and children less than five years have not been investigated in detail in the survey.

\section{Research question}

What are the key socio-economic predictors of mortality amongst South African children under the age of five years?

\section{Aims of the study}

The study aims to identify key socio-economic and healthrelated factors that may be responsible for mortality amongst South African children under five years based on the analysis of the 2003-SADHS. The study further seeks to propose feasible recommendations on the basis of the findings of the study to the South African National Department of Health.

\section{Literature review}

Statistics from the Union for African Population Studies (2009:2-5) reveal that some 11 million children under the age of five years die annually worldwide, out of which over 10 million deaths occur in the developing world. Sub-Saharan Africa is the region most affected, and accounts for more than one-third of all deaths amongst children under the age of five years. According to the World Health Organization (WHO) (2004:1-13), the majority of deaths amongst children under the age of five years is preventable, and occur in sub-Saharan African countries. According to the Joint United Nations Programme on HIV and AIDS (UNAIDS) (2009:2-14), child survival prospects remain dismal in Africa given the HIV and AIDS pandemic, the impact of poverty, famine and war. Sub-Saharan children who die before the age of five years are often characterised by poverty, illiteracy, the burden of occupational and communicable diseases, large family sizes, poor immunisation coverage rates and poor access to basic health and socio-economic services.

In sub-Saharan Africa under-five mortality is two to three times the average compared to any other region in the world. In over half of the 29 countries surveyed in sub-Saharan Africa, the mortality rate for children aged less than five years exceeds 150 deaths per 1000 live births. Under-five mortality levels are over 200 in the Democratic Republic of Congo, Burkina Faso, Mali, and the Central African Republic, and reach 259 deaths per 1000 live births in Niger (World Health Organization Statistical Information System 2009:12). United Nations agencies work with member states in Africa with a view to reduce child and maternal mortality, and have set up indicators for monitoring and evaluating progress made in terms of the reduction of the burden of disease and in terms 
of improvement in health service delivery. Based on these indicators, sub-Saharan African countries have failed to make satisfactory progress to date (United Nations Millennium Development Goals 2007:5). UNICEF (2007:12) has reported that the sub-Saharan average mortality rate for children younger than five years, in 2007, was 79 per 1000 live births. The World Bank (2009:1-4) has reported a similar finding. In 2000, countries in Central Africa had the highest underfive mortality rate with a median value of approximately 180 deaths per 1000 live births, indicating that there were no improvement from 1990 to 2000 (Union for African Population Studies 2009:14). Countries in East Africa showed a median of 160 deaths per 1000 live births, demonstrating a slight improvement from 1990 to 2000. The median for the West African region oscillated around 170 deaths per 1000 live births revealing that there were improvements from 1990 to 2000. African region reduced under-five mortality from a median of 60 deaths per 1000 live births to a median of 50 deaths per 1000 live births between 1990 and 2000. According to the World Bank (2009:7), the highest under-five mortality rate for an African country in 2005 was 168 deaths per 1000 live births. This figure was registered in a sub-Saharan African country. Progress has been particularly slow in subSaharan Africa following civil disturbances and the HIV and AIDS epidemic. According to the most recent data available, only 35 countries are making enough progress to be able to reduce under-five mortality rates to one-third of their 1990 level by 2015.

Figures published by the United Nations Statistics Division (2009:1-4) indicate that child mortality and morbidity could not be reduced significantly in most sub-Saharan African countries as a consequence of severe economic crisis, lack of economic and political stability, and the inability of national governments to make the necessary resources and infrastructure available to the rural population. The authors argue that recent mortality rate trends of children less than five years could be substantially reduced if governments were to demonstrate political commitment to meet the basic needs of children and mothers. Sub-Saharan Africa is the region most affected by poverty, which leads to child mortality and accounts for more than one-third of all deaths of children younger than five years. Numerous studies have shown a close association between child mortality and poor socio-economic status. Examples of socio-economic factors that adversely affect the survival of children in South Africa, amongst others, are (United Nations Statistics Division 2009:2-5):

- low income

- illiteracy amongst women aged 15 and above

- the percentage of the population living in poverty

- the high influx of rural people to urban areas in search of livelihood

- poor nutrition

- incomplete immunisation of infants

- lack of access to clean water

- lack of access to sanitation facilities.

The World Bank (2009:4-13) has reported that the majority of deaths amongst children under the age of five years are attributable to poverty, lack of access to basic health services and poor infrastructure. The main causes of death are perinatal conditions closely associated with poverty, diarrhoeal diseases, malaria, pneumonia and other lower respiratory tract conditions. Malnutrition increases the risk of dying from these diseases and contributes to more than half of all deaths of children younger than five years. A number of studies have identified a negative relationship between per capita income and mortality rate (UNAIDS 2009:1-14). There is a clear association between low household income and high mortality rate. As household income increases, the mortality rate amongst under-five children decreases. In most subSaharan African countries, poverty and under-five mortality are positively correlated. In a similar way as with income, urbanisation and illiteracy affect the mortality rate amongst children less than five years in the expected direction. The higher the percentage of the population living in urban areas, the lower is the mortality rate amongst children younger than five years, and the lower the percentage of illiterate women, the lower is the mortality rate amongst children younger than five years. The mortality rate amongst children less than five years is widely recognised as an important indicator of development. It is also the broadest, and hence most inclusive, widely used measure of child survival.

According to the UNICEF (2009:5), the root causes of mortality amongst under-five children in Africa, including South Africa, are:

- poor nutrition

- the level of awareness of the mother about basic health services

- access to basic health and education services

- the level of immunisation

- the ability of the mother to prepare oral rehydration solutions at home

- the availability of food

- sanitation

- cleanliness and safety of the living environment of the child.

Every hour, 10 children under the age of five years die from a preventable condition (Children's Institute 2006:14). Nannan et al. (2007:733-739) have reported that improving the nutritional status of children under the age of five years has the potential of reducing under-five mortality and morbidity (Table 1).

TABLE 1: Average numbers of deaths in South African provinces during 1998 and 2000.

\begin{tabular}{lcc}
\hline Province & Average numbers of deaths per 1000 live births per year \\
\cline { 2 - 3 } & $\mathbf{1 9 9 8}$ & $\mathbf{2 0 0 0}$ \\
\hline Eastern Cape & 80.5 & 105.0 \\
Free State & 19.0 & 99.0 \\
Gauteng & 45.3 & 75.0 \\
KwaZulu-Natal & 74.5 & 116.0 \\
Limpopo & 52.3 & 81.0 \\
Mpumalanga & 63.7 & 100.0 \\
Northern Cape & 55.5 & 68.0 \\
North West & 56.0 & 89.0 \\
Western Cape & 39.0 & 46.0 \\
South Africa & $\mathbf{5 9 . 4}$ & $\mathbf{9 5 . 0}$ \\
\hline
\end{tabular}

Source: Nannan, N., Norman, R., Hendricks, M., Dhansay., M.A. \& Bradshaw, D., 2007 'Estimating the burden of disease attributable to childhood and maternal under-nutrition in South Africa in 2000', South African Medical Journal 97(2), 733-739. PMid:17952231 
According to the South African Health Systems Trust (2009:1$9)$, in 2000, the under-five mortality rate was 95 deaths per 1000 live births. In 2004, the figure was reduced to 67 deaths. In 2003, the figure was further reduced to 58 deaths. Results from 1998 indicate that Black South African children experienced a higher mortality rate (63.6 deaths per 1000 live births) in comparison with Coloured South African children (28.2). According to the Community Survey conducted by Statistics South Africa (2007:49-82), inequalities in mortality rates are attributed to the legacy of racial discrimination and inequalities in the provision of basic health services in the past. According to Groenewald et al. (2005:744), although AIDS is known to increase under-five mortality, it is essential to improve basic health services in order to address the underlying causes of mortality and morbidity amongst South African children. Under-five mortality is the highest in KwaZulu-Natal and the Eastern Cape, and the lowest in the Western Cape. This is attributed to the fact that the Western Cape is much more adequately resourced in terms of infrastructure and access to health services. It is also worth noting that KwaZulu-Natal and the Eastern Cape are two provinces in which the HIV prevalence is high.

There has been very limited previous research into socioeconomic inequalities in child health in African countries. In South Africa, with its disparities between urban and rural populations, similar disparities are expected and have been previously demonstrated. Since 1994, South Africa has had a unitary national health system which provides the framework for integrated and comprehensive primary health care services for mothers and children. Free health care for children under the age of six years has been implemented since 1994. In South Africa diseases of poverty, which include low birth weight, diarrhoeal diseases, lower respiratory infections, and protein-energy malnutrition, account for $30 \%$ of all deaths. Dorrington et al. (2004:3) argue that the above causes of mortality collectively constitute diseases of poverty, because they can be prevented adequately by improving socio-economic conditions that adversely affect under-five children and their mothers.

The World Health Organization (2005:23) has reported that under-five mortality, poverty, unemployment and illiteracy, are most severe in the poorest and more rural-based provinces of South Africa. These findings are corroborated by the South African Health Systems Trust (2009:1-12), Khumalo (2008:20-32) and Statistics South Africa (2007:2-17). These provinces are the Eastern Cape, Limpopo, KwaZuluNatal and Mpumalanga, and they have the highest mortality rate for children younger than five years. This indicates that the following factors play an important role in reducing the mortality rate amongst children aged less than five years:

- socio-economic factors such as the nutritional and health status of mothers

- the level of education and awareness of mothers

- the level of immunisation and oral rehydration therapy use

- the availability of maternal and child health services

- the level of income and food availability in families
- the availability of clean water

- safe sanitation

- overall safety.

The four provinces are known to have on average poor populations with low levels of education and poor socioeconomic services to the general public.

With improved nutritional status, the risk of mortality amongst children under five years can be reduced, and their psycho-motor development enhanced. It is worth mentioning that, in South Africa, the mortality rate amongst children under five years is higher in the African and Coloured population groups, because of the legacies of past inequalities in the provision of basic socio-economic and health-related services.

The primary objective of the SADHS was to gather data on basic socio-economic and demographic variables such as age, gender, marital status, place of residence, level of education, level of income, language group, type of religion, type of occupation, ownership of home, family size, fertility and childhood mortality rates, access to health-related services such as immunisation, access to tap water, ownership of toilet, health education, access to family planning methods, maternal and child health, nutrition, breastfeeding, anthropometric variables, awareness about HIV and AIDS, environmental sanitation and other variables. The SADHS was a joint effort by various local and international stakeholders. The South African National Department of Health (2008:1-13) provided funds for the survey, and managed the survey. The South African Medical Research Council provided technical support. MACRO International, an American research institution that is funded by the USAID (United States Agency for International Development) for conducting largescale surveys globally, provided funds as well as technical support in areas such as study design, training of field staff, data entry and analysis. Statistics South Africa and the South African Human Sciences Research Council (HSRC) provided support in areas related to sampling frames.

\section{Research method and design Design}

The study design is cross-sectional and descriptive. This research is based on a secondary data analysis of the 2003-SADHS. Data were gathered from 7757 households selected from all over South Africa, using multi-stage cluster sampling. Sample selection was carried out in a series of steps. At Stage 1, census Enumeration Areas (EAs) and Primary Sampling Units (PSUs) were selected based on Probability Proportional to Size (PPS) according to the number of households in each EA. A total of 630 EAs were selected for the 2003-SADHS (368 from urban areas and 262 from rural areas). Stage 2 of the selection procedure involved the systematic sampling of households from selected EAs. The data set comprised 10 strata, one from each of the nine provinces and 1 more from all census EAs. Approximately 1000 households were allocated to each stratum. 
The sample drawn for the SADHS was designed to be a nationally representative probability sample of approximately 12000 completed interviews with women aged 15-49. The country was stratified into nine provinces and each province was further stratified into urban and rural areas. In addition, the Eastern Cape was stratified into five health regions, with each health region stratified into urban and rural areas. The sampling frame for the SADHS was a list of approximately 86000 enumeration areas (EAs) which had been created by Statistics South Africa for the 1996-census. Within each stratum, a two-stage sample was selected. The primary sampling units (PSUs) correspond to the EAs, and were selected with probability proportional to size (PPS), the size denoting the number of census visiting points at each EA. This led to a total of 972 PSUs being selected for the SADHS (690 in urban areas and 282 in rural areas). From each urban EA, 10 households were selected throughout the country. Every second household was selected for the adult health survey. In every second household, in addition to interviewing all women aged 15-49, interviewers also interviewed all men aged 15 and above as well as all women older than 49. It was expected that the sample would yield interviews with approximately 12000 women aged 15-49, and with 13500 adults. All technical aspects of the study were coordinated by Statistics South Africa (2003:1-23). All results of data analysis were obtained by treating the SADHS-2003 data set as a complex survey data set consisting of primary sampling units, strata, sampling weights for children under the age of five years, the duration of survival as well as the several predictor variables that affect the survival of children under the age of five years.

The data used for analysis in the current study is a subset of the data set gathered for SADHS-2003. As such, it only deals with 2221 children under the age of five years and their 1944 mothers. The 2221 children in this study were selected from 1944 households.

\section{Materials}

This study is based on a secondary data analysis of the SADHS conducted in 2003. The study population consists of all children less than five years born of mothers aged 15-49 who were interviewed in all nine provinces of South Africa as part of the 2003-SADHS.

\section{Inclusion criteria}

This study consists of 2221 South African children under the age of five years who were born during 1998-2003 to 1944 South African mothers aged 15-49 years. The 1944 mothers and their 2221 children were a subset of the sample drawn for SADHS-2003. There are a few households from where two or more under-five children were selected. Children were selected if their mothers were alive at the time the survey was conducted. Only mothers with verifiable physical addresses were selected for the study.

\section{Exclusion criteria}

Children with missing age information and children whose mothers had died were excluded from the survey. Women without a physical address were also excluded from the survey.

\section{List of variables of study}

The list of variables of the study was divided into two categories. The dependent or outcome variable of the study is the survival or death of an under-five child. A hundred of the 2221 children died prior to their fifth birthday; whereas 2121 of the 2221 children under the age of five years were alive at the time the survey was conducted. Duplicate children for households and mothers are considered independently for the purpose of logistic regression and Cox regression analysis because the number of duplicate children was relatively small (277 of the 2221). The independent variables comprised variables associated with under-five mortality. The outcome variable of the study is denoted by $Y$, and has only two possible outcomes: survival up to the age of five years, or death before the age of five years. For this reason, the event $Y=1$ denotes the death of an under-five child, whereas the event $Y=0$ denotes the survival of an under-five child. That is,

$Y=\left\{\begin{array}{l}1 \text { if an under }- \text { five child is dead } \\ 0 \text { if an under }- \text { five child is alive }\end{array}\right.$

[Eqn 1]

\section{Independent variables of study $\left(X_{1}, X_{2}, \ldots, X_{k}\right)$}

The independent variables consisted of several socioeconomic, demographic, health-related and sanitary variables that are associated with under-five mortality. For the purpose of performing logistic regression and survival analysis, the following variables were used for data analysis:

- the duration (months) of breastfeeding (breastfed for six months or more, other)

- nutrition (good, poor)

- marital status of mother (never married, married, living together, widowed, divorced, not living together)

- mother's level of education (primary level or less, other)

- the immunisation status of the child (complete, incomplete)

- income level of household (low, moderate or better)

- mother's place of residence (rural, urban)

- access to clean water (yes, no)

- access to flush toilet (yes, no)

- place of delivery of child (inside a health facility, elsewhere)

- mother's age at the birth of the child (21 or more, younger than 21)

- use of modern family planning methods (yes, no).

Household income was defined as a function of the wealth index of the household in which wealth was measured based on a standardised scale designed for measuring wealth at the household level based on ownership of assets.

\section{Data analysis}

Suitable statistical procedures were used for exploring and quantifying the relationship between the outcome variable used for analysis and the various predictors of under-five mortality. This was performed by obtaining: 
- frequency tables for categorical variables

- summary statistics for continuous variables

- Pearson's Chi-square tests of association (Dawson \& Trapp 2004)

- Cramer's V statistic (Agresti 2003)

- survey-logistic-regression analysis (Hosmer \& Lemeshow 2002).

These procedures led to the identification of a manageable size of predictor variables that were used for subsequent data analysis based on the Cox proportional hazards model (Cleves, Gould \& Guitierrez 2004). Odds ratios and hazard ratios were used as an epidemiological measure of effect. Adjustment was factored in for potential confounding variables. The statistical package, STATA version 11 (STATA Corporation 2010) was used for data analysis. Sampling weights were calculated. Hazard ratios were used as an epidemiological measure of effect for survival analysis.

\section{Results}

\section{Frequency tables and summary statistics}

The gender distribution, as well as the survival status, of the 2221 children in the subsample selected for this analysis from SADHS-2003, has been presented (Table 2). The subsample of 2221 children and their 1944 mothers comprised all provinces and population groups in South Africa. A hundred of the 2221 children died prior to their fifth birthday; whereas 2121 of the 2221 children under the age of five years were alive at the time the survey was conducted.

One hundred of the 2221 children (4.5\%) in the subsample died before reaching the age of five years (Table 2). The 2221 children were born to 1944 mothers. The 2221 children in the subsample comprised 1125 (50.65\%) boys, and 1096 (49.35\%) girls (Table 2). Some women had a boy and a girl, whereas others had two children of the same sex. There are not many 'duplicates' per household or per mother (277 out of 2221 [12.5\%]), and consequently it is assumed that the children in the study satisfy the assumption of independence. Out of the 100 children who died, 91 (91\%) were younger than twelve months, eight (8\%) died when they were older than a year but younger than two years, and one child died at an age older than two years (twenty-four months). The average age of the 2221 children in the SADHS-2003 data set that were under the age of five years was 29.05 months ( $\mathrm{SE}=0.43 ; 95 \% \mathrm{CI}$ of $28.21-29.89$ months). The lower and upper confidence limits of the $95 \% \mathrm{CI}$ indicate that the average age of the under-five children in the data set lay between two and three years at the time the survey was conducted.

It can be seen from the age distribution that $22 \%$ of the 2221 children selected were infants (Table 3).

The largest proportion of children was Black or African (75.55\%), followed by Coloured children (15.94\%), Asian or Indian $(5.76 \%)$, and White children $(2.70 \%)$, (Table 4$)$. The proportion of urban children $(55.20 \%)$ in the study sample was larger than that of rural children (44.80\%).
TABLE 2: Profile of children whose mothers participated in the survey $(N=2221)$.

\begin{tabular}{lcc}
\hline Variable of study & $\boldsymbol{n}$ & $\mathbf{\%}$ \\
\hline Survival & & \\
Yes & 2121 & 95.50 \\
No & 100 & 4.50 \\
Total & 2221 & 100.00 \\
Sex & & \\
Male & 1125 & 50.65 \\
Female & 1096 & 49.35 \\
Total & 2221 & 100.00 \\
\hline
\end{tabular}

Source: The South African Demographic Health Survey (2003)

$N$, total number of participants; $n$, given as means of number.

TABLE 3: Age distribution of children selected for analysis $(N=2221)$.

\begin{tabular}{lcc}
\hline Age category (months) & $\boldsymbol{n}$ & $\mathbf{\%}$ \\
\hline$\leq 12$ & 486 & 21.88 \\
$13-24$ & 414 & 18.64 \\
$25-36$ & 430 & 19.36 \\
$37-48$ & 397 & 17.87 \\
$49-60$ & 494 & 22.24 \\
\hline Total & $\mathbf{2 2 2 1}$ & $\mathbf{1 0 0 . 0 0}$ \\
\hline
\end{tabular}

Source: The South African Demographic Health Survey (2003)

$N$, total number of participants; $n$, given as means of number.

TABLE 4: General characteristics of children $(N=2221)$.

\begin{tabular}{|c|c|c|}
\hline Demographic variables & $n$ & $\%$ \\
\hline \multicolumn{3}{|l|}{ Ethnicity of child } \\
\hline Black or African & 1678 & 75.55 \\
\hline Coloured & 354 & 15.94 \\
\hline White & 60 & 2.70 \\
\hline Asian or Indian & 128 & 5.76 \\
\hline Other & 1 & 0.05 \\
\hline Total & 2221 & 100.00 \\
\hline \multicolumn{3}{|l|}{ Province of child } \\
\hline Western Cape & 253 & 11.39 \\
\hline Eastern Cape & 178 & 8.01 \\
\hline Northern Cape & 288 & 12.97 \\
\hline Free State & 235 & 10.58 \\
\hline KwaZulu-Natal & 164 & 7.38 \\
\hline North West & 275 & 12.38 \\
\hline Gauteng & 231 & 10.40 \\
\hline Mpumalanga & 296 & 13.33 \\
\hline Limpopo & 301 & 13.55 \\
\hline Total & 2221 & 100.00 \\
\hline \multicolumn{3}{|l|}{ Residential area of child } \\
\hline Urban & 1226 & 55.20 \\
\hline Rural & 995 & 44.80 \\
\hline Total & 2221 & 100.00 \\
\hline
\end{tabular}

Source: The South African Demographic Health Survey (2003)

$N$, total number of participants; $n$, given as means of number.

Mothers in the age groups 20-24 and 25-29 accounted for roughly $25 \%$ each of the 1944 mothers in the study sample (Table 5). The average age of the 1944 mothers in the study sample were 27.17 years. Mothers younger than 20, comprised $134(6.9 \%)$ of the total number. Nearly $40 \%$ of the 1944 mothers in the study sample were never married or they were single; $38 \%$ of them were married or living together with their sexual partners; and approximately $5 \%$ were married, but not living with their sexual partners (Table $5)$. The majority of mothers $(66 \%)$ had acquired secondary or tertiary level education whilst $5 \%$ had no formal education, 
and more than a quarter $(29 \%)$ of mothers had primary level education.

A large proportion of mothers $(88.42 \%)$ had access to piped water and flush toilets (49\%), (Table 6). Furthermore, about $79 \%$ of mothers had access to electricity whilst approximately $63 \%$ had access to a television and a refrigerator (59\%). Small numbers of women (16.25\%) had access to a bicycle, a motorcycle (2\%), and a car or truck (21\%) (Table 6).

The distribution of households according to the wealth index, as a measure of economic status has been indicated (Table 7). The data set gathered in SADHS-2003 does not collect reliable data on household income or expenditure, but does provide information on household assets. Principal Component Analysis (Hill \& Lewicki 2007) was conducted based on the ownership of 25 standard assets that served as a measure of economic status at the household level. A weighted asset index was generated and used for dividing the 1944 households in this study into five wealth quintiles. The resulting asset scores were standardised based on the standard normal distribution with a mean of zero and a standard deviation (s.d.) of one unit. The standardised scores were then used to create the break points that defined five wealth quintiles (lowest, second lowest, middle, fourth, and highest) at the household level.

The lowest wealth index category consists of households with standardised wealth indices less than 20\%, and represents households that are below the poverty level. The second lowest wealth index category consists of households with standardised wealth indices between $20 \%$ and $40 \%$, and represents households that are poor. The middle-wealth index category consists of households with standardised wealth indices between $40 \%$ and $60 \%$, and represents middleincome households. The fourth wealth index category consists of households with standardised wealth indices between $60 \%$ and $80 \%$, and represents rich households. The highest wealth index category consists of households with standardised wealth indices above $80 \%$, and represents the richest households. The table shows that the majority of households $(24.41 \%)$ were in the middle class. It can be seen that $24.10 \%$ of the 1944 households in this study were poor, whilst $20.45 \%$ were below the poverty level.

\section{Results from the Pearson Chi-square tests of association}

Pearson's Chi-square tests of association were performed between the death of a child under the age of five years and several socio-economic and demographic variables of interest. All expected cell frequencies were above five, thereby showing that results obtained from Pearson's Chisquare tests of association were valid. $P$-values and observed Chi-square values were used as a measure of statistical significance. The tests were performed at the 0.05 level of significance. At the 5\% level, significant associations are characterised by $P$-values that are smaller than 0.05 and Cramer's $V$-values that are close to 1 .
TABLE 5: General characteristics of mothers $(N=1944)$.

\begin{tabular}{lcc}
\hline Variable & $\boldsymbol{n}$ & $\boldsymbol{\%}$ \\
\hline Age category & 134 & 6.89 \\
$15-19$ & 485 & 24.94 \\
$20-24$ & 482 & 24.81 \\
$25-29$ & 395 & 20.31 \\
$30-34$ & 281 & 14.45 \\
$35-39$ & 129 & 6.66 \\
$40-44$ & 38 & 1.94 \\
$45-49$ & 1944 & 100.00 \\
Total & & \\
Marital Status & 774 & 39.81 \\
Never married or single & 743 & 38.22 \\
Married and living together & 288 & 14.82 \\
Not married, but living together & 26 & 1.34 \\
Widowed & 27 & 1.39 \\
Divorced & 86 & 4.42 \\
Married, but not living together & 1944 & 100.00 \\
Total & & \\
Level of education & 95 & 4.89 \\
No schooling & 568 & 29.22 \\
Primary level education & 1281 & 65.89 \\
High school or higher & 1944 & 100.00 \\
Total & &
\end{tabular}

Source: The South African Demographic Health Survey (2003)

$N$, total number of participants; $n$, given as means of number.

TABLE 6: Distribution of household resources $(N=1944)$.

\begin{tabular}{lcc}
\hline Household resources & $\boldsymbol{n}$ & $\mathbf{\%}$ \\
\hline Piped water & 1719 & 88.43 \\
Flush toilet & 1080 & 55.56 \\
Electricity & 1529 & 78.65 \\
Radio & 1387 & 71.35 \\
Television & 1222 & 62.86 \\
Refrigerator & 1148 & 59.05 \\
Bicycle & 312 & 16.05 \\
Motorcycle & 27 & 1.39 \\
Car or truck & 401 & 20.63 \\
\hline
\end{tabular}

Source: The South African Demographic Health Survey (2003)

$N$, total number of participants; $n$, given as means of number

TABLE 7: Distribution of households by the wealth index quintile $(N=1944)$.

\begin{tabular}{lcc}
\hline Wealth Index Quintile & $\boldsymbol{n}$ & $\mathbf{\%}$ \\
\hline Richest households & 284 & 14.62 \\
Rich households & 320 & 16.46 \\
Middle-income households & 474 & 24.38 \\
Poor households & 468 & 24.07 \\
Households below the poverty line & 398 & 20.47 \\
\hline Total & $\mathbf{1 9 4 4}$ & $\mathbf{1 0 0 . 0 0}$
\end{tabular}

Source: The South African Demographic Health Survey (2003)

$N$, total number of participants; $n$, given as means of number

Based on results shown in Table 8, the loss of a child is significantly associated with variables such as ownership of a flush toilet facility, failure to breastfeed children for six months or more, failure to have children fully immunised, poor nutrition, poor access to clean water, and poor attendance of antenatal and postnatal health care services. The remaining variables in the table did not have a significant association with the loss of a child. It must be noted that results from the Pearson Chi-square test of association are not theoretically 
as reliable as results obtained from logistic regression analysis or Cox regression. This is because Chi-square tests of association take into account the strength of association between two variables only, at a time, disregarding the effect of all other variables in the model (Dawson \& Trapp 2004).

\section{Results from survey logistic regression analysis}

Results obtained from survey logistic regression analysis (Table 9) indicate that the loss of an under-five child is influenced by six of the nine predictor variables used for analysis, and were influential predictors of survival at the 0.05 level of significance. These six influential predictor variables were ownership of a flush toilet facility, marital status, breastfeeding (yes, no), literacy status, mother's residential area, and mother's age at first birth. For the purpose of simplifying the task of interpreting odds ratios estimated from logistic regression analysis, the variable 'literacy status' was dichotomised into two categories (' 1 ' if the mother had no formal education, ' 0 ' if otherwise). Similarly, the variable 'marital status' was dichotomised into two categories (' 1 ' if mother was married, ' 0 ' if otherwise).

The adequacy of the fitted survey logistic regression model was assessed using the classification table, the Hosmer-Lemeshow goodness-of-fit test, the likelihood-ratio test, and the design effect. The percentage of overall correct classification was $89.48 \%$. As this figure is well above $75 \%$, the fitted logistic regression model has the capacity for classifying observed data fairly accurately. The classification rate before predictor variables were included in the model was $72.03 \%$. Hence, the improvement achieved in classification equals $17.45 \%$, and is attributed to the predictor variables selected for analysis. The $P$-value obtained from the Hosmer-Lemeshow goodnessof-fit test was $0.673>0.05$, thereby showing that the fitted model is adequate at the $1 \%$ level. All estimated values of the design effect in this study were lower than two. This small value confirms that the sampling design used for the study is reasonably efficient, and that the fitted model corresponds to the data.

\section{Results from survival analysis}

Results obtained from the Cox Proportional Hazards Model (survival analysis) are notably more appropriate than those obtained from logistic regression analysis, because the study design for this part of the analysis is longitudinal. The age of the child is used as a proxy for survival time. The survival status of children (dead or alive) is used as an indicator of censored observations. Survival time was regressed on nine possible influential dichotomous $(1,0)$ variables that affect under-five mortality through the use of the Cox Proportional Hazards Model. The epidemiological measure of effect is the hazard ratio. At the 5\% level of significance, significant hazard ratios are characterised by hazard ratios that are significantly different from ' 1 ',$P<0.05$, and $95 \% \mathrm{CI}$ of hazard ratios that do not contain ' 1 '.

Three of the nine predictor variables used for analysis were significant at the 5\% level (Table 10). These variables were breastfeeding (yes, no), marital status, and ownership of a flush toilet.

The hazard ratio of the variable, breastfeeding (yes, no), is 3.09. This indicates that a mother, who does not breastfeed her child, is 3.09 times as likely to have lost a child as a woman who does breastfeed her child.

The hazard ratio of the variable 'marital status' is 1.74 . This shows that a married mother is 1.74 times as likely to have lost a child as an unmarried mother.

The hazard ratio of the variable 'toilet' is equal to 2.35. This suggests that a mother who does not have a flush toilet is 2.35 times as likely to have lost a child as a mother who has a flush toilet.

Adjustment was factored in for the mother's level of education and the wealth index. These two variables are

TABLE 8: Association of death of under-five children with selected variables of study using the Pearson Chi-square tests ( $N=2221)$.

\begin{tabular}{|c|c|c|c|c|}
\hline Variable & Categories & $X^{2}$ & $P$-value & Cramer's $V$-value \\
\hline Access to clean water & Yes OR No & 5.03 & 0.0000 & 0.6961 \\
\hline Full immunisation & Yes OR No & 86.94 & 0.0000 & 0.5641 \\
\hline Nutrition status of child & Adequate OR Inadequate & 32.65 & 0.0000 & 0.7871 \\
\hline Access to toilet facility & Yes OR No & 29.75 & 0.0018 & 0.1405 \\
\hline Ownership of flush toilet & Yes OR No & 30.18 & 0.0108 & 0.1075 \\
\hline Regular attendance of ANC and PNC services & Yes OR No & 30.29 & 0.0013 & 0.1401 \\
\hline Formal education of mother & Yes OR No & 0.92 & 0.7992 & 0.0393 \\
\hline Wealth Index Quintile & Poor OR Average or better & 8.50 & 0.3407 & 0.0587 \\
\hline Age of mother at first birth $\geq 21$ & Yes OR No & 11.58 & 0.2101 & 0.0496 \\
\hline Delivery of child inside a health facility & Yes OR No & 7.11 & 0.5232 & 0.0623 \\
\hline Breastfeeding for $\geq 6$ months & Yes OR No & 28.20 & 0.0000 & 0.7123 \\
\hline Access to electricity & Yes OR No & 0.46 & 0.6253 & 0.0411 \\
\hline Residential area & Rural OR Urban & 1.71 & 0.3742 & 0.0859 \\
\hline
\end{tabular}

Source: The South African Demographic Health Survey (2003)

ANC, antenatal clinic; PNC, postnatal clinic.

$N$, Total number of participants; $X^{2}$, Chi-square observed value.

Significance, $P<0.05$ 
TABLE 9: Logistic regression analysis for under-five mortality $(N=2221)$.

\begin{tabular}{|c|c|c|c|}
\hline Characteristic & $\begin{array}{c}\text { Adjusted Odds } \\
\text { Ratio* }\end{array}$ & $95 \% \mathrm{Cl}$ & $P$-value \\
\hline \multicolumn{4}{|l|}{ Residential area } \\
\hline Urban† & 1.00 & - & - \\
\hline Rural & 0.36 & $0.142-0.889$ & 0.027 \\
\hline \multicolumn{4}{|l|}{ Access to clean water } \\
\hline Yes $\dagger$ & 1.00 & - & - \\
\hline No & 1.09 & $0.853-1.412$ & 0.470 \\
\hline \multicolumn{4}{|l|}{ Ownership of flush toilet } \\
\hline Yest & 1.00 & - & - \\
\hline No & 2.15 & $1.405-3.28$ & 0.000 \\
\hline \multicolumn{4}{|l|}{ Literacy status of mother } \\
\hline Literate $\dagger$ & - & - & - \\
\hline Illiterate & 0.73 & $0.542-0.982$ & 0.038 \\
\hline \multicolumn{4}{|l|}{ Marital status of mother } \\
\hline Married $\dagger$ & 1.00 & - & - \\
\hline Other & 1.29 & $1.075-1.556$ & 0.007 \\
\hline \multicolumn{4}{|l|}{ Income } \\
\hline Moderate or better $\dagger$ & 1.00 & - & - \\
\hline Low & 0.83 & $0.607-1.116$ & 0.208 \\
\hline \multicolumn{4}{|l|}{ Mother's age at first birth } \\
\hline$\geq 21 \dagger$ & 1.00 & - & - \\
\hline$<21$ & 0.75 & $0.575-0.971$ & 0.029 \\
\hline \multicolumn{4}{|l|}{ Place of delivery of child } \\
\hline Health facility $\dagger$ & 1.00 & - & - \\
\hline Outside a health facility & 1.03 & $0.774-1.366$ & 0.849 \\
\hline \multicolumn{4}{|l|}{ Breastfeeding } \\
\hline 6 months or more $\dagger$ & 1.00 & - & - \\
\hline Other & 1.34 & $1.165-1.538$ & 0.000 \\
\hline
\end{tabular}

Source: The South African Demographic Health Survey (2003)

$\dagger$, Denotes reference category.

$\star$, Adjustment the mother's level of education and the wealth index.

$N$, The total number of participants; $\mathrm{Cl}$, Confidence Interval; Significance, $P<0.05$

potential confounding variables according to the literature reviewed. However, adjusted and unadjusted hazard ratios did not differ significantly from each other. Hence, none of the variables employed for adjustment was a confounding or effect-modifying variable.

The Kaplan-Meier survival probability plot (Figure 1) represents the comparison of children with regard to breastfeeding (yes, no). The plot illustrates that children who were breastfed had considerably larger survival probabilities, by a factor of 3.09, in comparison with children who were not breastfed adequately. Breastfeeding for less than six months is considered inadequate. This finding is consistent with findings based on a comparative study of Native American and White American infants as reported by Winkley, Cubbin and Aim (2006:12-34) as well as Chertok (2007:50-54).

The constant hazard function assumption in the Cox Proportional Hazards Model was verified log-minus-log plots. The goodness of the fitted Cox regression model was assessed through the use of the AIC (Akaike Information Criterion) statistic. The AIC statistic is a measure of discrepancy between the ideal and the estimated fit. The estimated value of the AIC statistic in this study was 10.34, a relatively small value, which indicates that the fitted model is acceptable.
TABLE 10: Survival analysis for under-five mortality.

\begin{tabular}{|c|c|c|c|}
\hline Characteristic & $\begin{array}{c}\text { Adjusted Hazard } \\
\text { Ratio: }\end{array}$ & $95 \% \mathrm{Cl}$ & $P$-value \\
\hline \multicolumn{4}{|l|}{ Residential area } \\
\hline Urban† & 1.00 & - & - \\
\hline Rural & 0.80 & $0.449-1.410$ & 0.434 \\
\hline \multicolumn{4}{|l|}{ Access to clean water } \\
\hline Yes $\dagger$ & 1.00 & - & - \\
\hline No & 0.94 & $0.414-2.137$ & 0.884 \\
\hline \multicolumn{4}{|l|}{ Ownership of flush toilet } \\
\hline Yest & 1.00 & - & - \\
\hline No & 2.35 & $1.172-4.707$ & 0.016 \\
\hline \multicolumn{4}{|l|}{ Literacy status of mother } \\
\hline Literate $\dagger$ & - & - & - \\
\hline Illiterate & 0.18 & $0.024-1.278$ & 0.086 \\
\hline \multicolumn{4}{|l|}{ Marital status of mother } \\
\hline Married $\dagger$ & 1.00 & - & - \\
\hline Other & 1.74 & $1.041-2.912$ & 0.035 \\
\hline \multicolumn{4}{|l|}{ Income } \\
\hline Moderate or betteri & 1.00 & - & - \\
\hline Low & 1.51 & $0.837-2.724$ & 0.171 \\
\hline \multicolumn{4}{|l|}{ Mother's age at first birth } \\
\hline 21 or above $\dagger$ & 1.00 & - & - \\
\hline Below 21 & 0.67 & $0.367-1.239$ & 0.204 \\
\hline \multicolumn{4}{|l|}{ Place of delivery of child } \\
\hline Health facility $\dagger$ & 1.00 & - & - \\
\hline Outside a health facility & 1.42 & $0.649-3.101$ & 0.381 \\
\hline \multicolumn{4}{|l|}{ Breastfeeding } \\
\hline 6 months or more $\dagger$ & 1.00 & - & - \\
\hline Other & 3.09 & $1.899-5.033$ & 0.000 \\
\hline
\end{tabular}

Source: The South African Demographic Health Survey (2003)

$\dagger$, Denotes reference category.

\pm , Adjustment the mother's level of education and the wealth index.

$\mathrm{Cl}$, Confidence Interval; Significance, $P<0.05$

\section{Ethical considerations}

Ethical clearance was granted by the South African National Department of Health for the primary data set. The 2003-SADHS data set is freely available at the South African National Department of Health. No permission was required for analysing the data set as this study involved a secondary analysis of the SADHS.

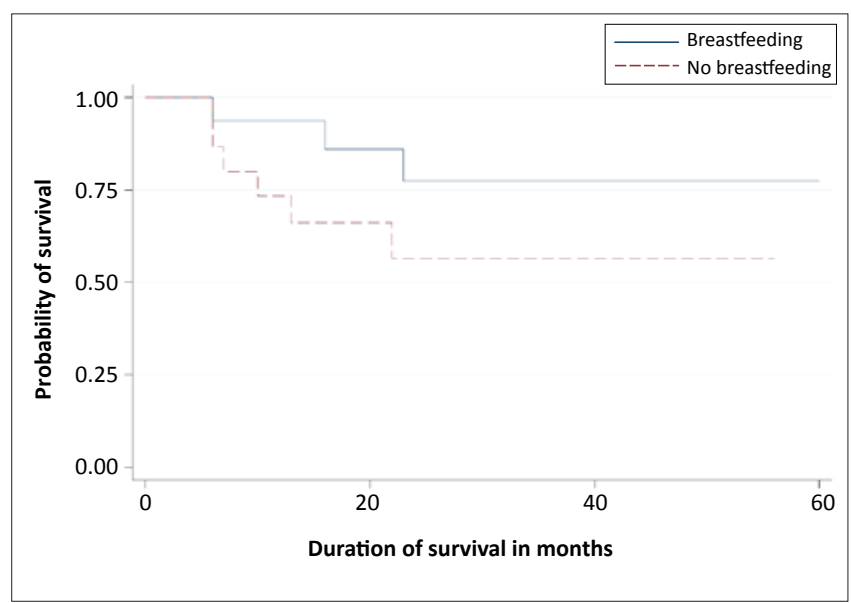

Source: The South African Demographic Health Survey (2003)

FIGURE 1: Kaplan-Meier survival probability plot of breastfeeding. 


\section{Validity and reliability}

Validity was used for ensuring that instruments used in the study, measure the information we intended to measure. Precise measurements can be reproduced readily under similar circumstances by suitably trained data collectors, which indicate the reliability of the study. In this study, issues related to validity (external and internal) and reliability were adequately addressed by the South African National Department of Health at the stage when the primary study was designed and implemented.

\section{Discussion}

Findings from this study are broadly in line with comparative findings from other developing countries in sub-Saharan Africa. The study indicates that the survival of children could be improved by improving access to basic health and socioeconomic services to the general population, with particular attention to rural mothers and children. Based on findings of this study, the current under-five mortality rate of 58 per 1000 live births could be attributed to poor health service delivery, the spread of HIV and AIDS, illiteracy and unemployment amongst rural mothers, and abject poverty amongst the rural population of South Africa. The study clearly demonstrates that rural, poor women and their children are particularly disadvantaged as a result of inequality in the provision of basic health services (Khumalo 2008:7-10). This finding is in agreement with what has been reported widely in the literature about the negative impact of HIV and AIDS in South Africa (Declercq et al. 2009:929-935).

The lack of reliable and timely health information on basic health and socio-economic services in South Africa is a major obstacle to proper research, sound planning, as well as monitoring and evaluation activities that could be used for assessing progress made by the government. Consequently, the task of reducing the current under-five mortality rate becomes a major challenge to the South African Department of Health. Education is still not freely available in South Africa. As a result, impoverished rural mothers are unable to empower themselves by acquiring formal and reproductive knowledge. They cannot access health services that are available to other population groups because of their abject poverty. This is a clear indication that the national government must alleviate abject poverty amongst povertystricken, illiterate, rural mothers.

According to Maluleke and Worku (2009:2354-2374), ownership of flush toilets is a reliable indicator of wealth and social status in South Africa. Poverty-stricken South African mothers and their children cannot afford flush toilets. Although Rural Development Programme (RDP) homes have been constructed in selected rural regions of South Africa since 1994, the number RDP homes supplied, is far below the number desperately needed. Based on the hazard ratio of the variable 'toilet' (2.35), it is clear that a child whose parents do not have access to a flush toilet facility is 2.35 times more likely to die before celebrating his or her fifth birthday, in comparison with another child whose parents have access to a flush toilet facility.

South Africa is a young democracy. Prior to 1994, Black people were marginalised and they had no access to proper toilet facilities. Even those who lived in townships mostly used the bucket system in which people have to carry water in buckets in order to clean up their faeces at awkward spots. In South Africa, the ability to maintain personal hygiene in a household depends on socio-economic status, and is a key determinant of the survival of children. In most rural households, failure to maintain proper sanitation is associated with the occurrence of diarrhoeal diseases in rural households. Diarrhoeal diseases are responsible for approximately $25 \%$ of the under-five mortality rate in subSaharan Africa. Developed nations of the world have $96 \%$ - $100 \%$ access to proper sanitation, and hence their underfive mortality rates are significantly lower than those in subSaharan Africa (UNAIDS 2009:1-16).

The study suggests that breastfed children have a better chance of survival compared to those who are not breastfed. The hazard ratio of 3.09 verifies that a child who is not breastfed is 3.09 times as likely to die before celebrating his or her fifth birthday, in comparison with another child who is breastfeed for at least six months. The ability of the mother to breastfeed the child exclusively depends on her socio-economic status. According to the National Institutes of Health (2004:1-2), poverty-stricken rural mothers cannot afford to breastfeed their new-borns exclusively for six months or longer because they are obliged to fetch water and firewood, work on the farms, look after cattle, cook for the whole family, wash clothes, and go to the market. Besides, most rural mothers give birth frequently, and are not always adequately aware of the crucial importance of exclusive breastfeeding for the survival of their new-born. Family planning methods are poorly utilised by rural, illiterate mothers. The research conducted by Kakute et al. (2005:324328) in Cameroon has corroborated these findings by the National Institutes of Health.

The value of education and literacy has been clearly established in this study. The study confirms that the level of education of the mother is associated with the loss of a child. The odds of death amongst children born to uneducated mothers are higher than the odds of death amongst children born to educated mothers by a factor of $27 \%$. The fact that fewer years of formal schooling is associated with the loss of a child shows that education is notably helpful for reducing mortality amongst under-five children. Rural mothers, for example, do not necessary know how to prepare oral rehydration solutions during winter. They may not know the value of full immunisation or proper environmental sanitation.

It is evident from the study that urban children are more likely to survive than rural children. The study also shows that urban children are less likely, by a factor of $64 \%$, to die 
compared to urban children. This difference may be attributed to the inability to access basic health care services, proper sanitation, access to safe water, employment opportunities, and so forth.

The marital status of the mother is associated with the survival of the child. The odds of death of children born to single mothers are 1.3 times higher than the odds of death of children born to married mothers. The hazard ratio is 1.74 , and this indicates that a child whose parents are single is 1.74 times as likely to die before celebrating his or her fifth birthday, in comparison with a child whose parents are married or living together. Clearly, both parents have the potential for contributing much more to the well-being of the child than a single parent.

Large areas of South Africa are rural, such as the Eastern Cape, KwaZulu-Natal and Limpopo. Hence, these regions are the poorest of the poor regions in South Africa. Infrastructural development is very low in these regions, with a disproportionately low number of health facilities and qualified medical personnel. The survival of a child is therefore affected by the type of place of delivery. In rural areas where there are no health facilities nearby, children may be born without the assistance of properly trained birth attendants. Furthermore, access to electricity and water are crucial factors that affect mortality. The rural population is thus clearly disadvantaged because access to electricity and water is a major problem in rural areas.

\section{Limitations of study}

Although the SADHS was conducted in 2003, the data set as well as interim results of the survey were only released much later. Seven years have passed since the survey was conducted.

The study is based on the analysis of the survival times of 2221 children under the age of five years. Data on these children were taken from SADHS-2003 in order to perform survival analysis. The 2221 children in this study have not been followed up since birth. As a result, some measurement bias could have been introduced.

\section{Recommendations}

Based on findings of this study, the following recommendations are made to the South African Department of Health so that, where possible, remedial actions could be taken with a view to reduce mortality amongst South African children under the age of five years:

- The National Government must provide improved access to basic health services to rural mothers and their children.

- Health education must be provided to rural mothers so that they can benefit from primary health care programmes and procedures, personal hygiene and proper waste disposal.
- The bucket system of toilets should be discarded by providing the rural population with flush toilets. Although the government has made a commitment to eliminate the bucket system of toilets by the year 2014, this goal is unlikely to be met in 2014. The task must be pursued with enough vigour, adequate resources and the necessary political commitment.

- Community based initiatives should be used amongst the rural population in order to create job opportunities for poor, rural mothers and to empower them economically. The unemployment rate amongst rural mothers and the gap between the rich and the poor are major problems that must be addressed by the National Government. Young rural mothers leave their children and habitat for urban centres in search of jobs and livelihood. This is particularly true of single mothers.

- Feeding and nutrition programmes are necessary in poor provinces such as the Eastern Cape, KwaZulu-Natal and Limpopo.

\section{Conclusion}

The study has shown that under-five mortality is affected by the practice of breastfeeding, the mother's marital status, and the mother's level of education, ownership of flush toilet facilities, the residential area and place of delivery of the child. Based on results obtained from Pearson's Chi-square tests of association, children who died are characterised by a low immunisation-coverage rate $(P=0.0000)$, poor nutrition $(P=0.0000)$, poor access to tap water $(P=0.0000)$, no access to flush toilets $(P=0.0108)$ and the children belonged to rural and unemployed mothers who did not attend antenatal and postnatal health care services $(P=0.0013)$. This indicates that rural mothers and children are relatively disadvantaged with regard to basic health services in comparison with urban mothers and children.

\section{Acknowledgements}

The author wishes to thank the South African Medical Research Council for providing the raw data set on children aged less than five years, their mothers and caretakers. The author also wishes to thank the Research Committee of Tshwane University of Technology for providing financial assistance for the study.

\section{Competing interests}

The author declares that he has no financial or personal conflict of interest in so far as this research exercise is concerned.

\section{Authors' contributions}

The raw data set on children under the age of five years was extracted from the master file by the South African Medical Research Council. Data editing and verification was done by M.K. of the School of Health Systems and Public Health of the University of Pretoria. 


\section{References}

Agresti, A., 2003, Categorical Data Analysis, 2nd edn., John Wiley and Sons, New York. doi:10.1002/0471249688

Chertok, I.R., 2007, 'The importance of exclusive breastfeeding in infants at risk for celiac disease', The American Journal of Maternal and Child Nursing 32(1), 50-54.

Children's Institute, 2006, 'Under-five mortality rate in South Africa by province and sex for 2000', viewed 02 February 2011, from http://www://childrencount. ci.org.za

Cleves, M., Gould, W. \& Gutierrez, R., 2004, An Introduction of Survival Analysis Using STATA, 2nd edn., STATA Press, Houston, Texas, USA.

Dawson, B. \& Trapp, R.G., 2004, Basic and Clinical Biostatistics, 4th edn., McGraw Hill, New York.

Declercq, E., Labbok., M.H, Sakala, C. \& O'Hara, M.A., 2009, 'Hospital practices and women's likelihood of fulfilling their intention to exclusively breastfeed', American Journal of Public Health 99(5), 929-935. doi:10.2105/AJPH.2008.135236, PMid:19299680, PMCid:2667852

Dorrington, R.E., Bradshaw, D., Johnson L. \& Budlender, D., 2004, 'The demographic impact of HIV/AIDS in South Africa', viewed 02 February 2011, from http://www. mrc.ac.za/bod/demographic.pdf

Groenewald, P., Bradshaw, D., Dorrington, R., Bourne, D., Laubscher, R. \& Nannan N., 2005, 'Identifying deaths from AIDS in South Africa: an update', AIDS 19(7), 744-744. doi:10.1097/01.aids.0000166105.74756.62, PMid:15821408

Hill, T. \& Lewicki, P., 2007, 'Statistics Methods and Applications', StatSoft: Tulsa, Oklahoma.

Hosmer, D.W. \& Lemeshow, S., 2002, Applied Logistic Regression, John Wiley \& Sons, New York.

Kakute, P., Ngum, J., Mitchell, P., Kroll, K., Forgwei, G., Ngwang, L. \& Meyer, D. 2009, 'Cultural barriers to exclusive breastfeeding by mothers in a rural area of Cameroon, Africa', Journal of Midwifery and Women's Health 50(4), 324-328. doi:10.1016/j.jmwh.2005.01.005

Khumalo, M., 2008, 'Key socio-economic predictors of mortality among children less than five years of age in South Africa: An analysis of the 2003 South African Demographic and Health Survey data set', BSc Honours thesis, School of Health Systems and Public Health, University of Pretoria.

Maluleke., K.R. \& Worku, Z., 2009, 'Environmental Determinants of Asthma among School Children Aged 13-14 in and around Polokwane, Limpopo Province, South Africa', International Journal of Environmental Research in Public Health 6(9), 2354-2374. doi:10.3390/ijerph6092354, PMid:19826548, PMCid:2760414

Nannan, N., Norman, R., Hendricks, M., Dhansay., M.A. \& Bradshaw, D., 2007 'Estimating the burden of disease attributable to childhood and maternal undernutrition in South Africa in 2000', South African Medical Journal 97(2), 733-739. PMid:17952231
National Institutes Of Health, 2004, 'Breastfeeding decreases infant mortality', viewed 02 February 2011, from http://www.nih.gov/news/pr/may2004/niehs-02.htm

South African Health Systems Trust, 2009, 'Health statistics: Indicators in child health', viewed 02 February 2011, from http://new.hst.org.za/hstindicators/subind/ indtype/003001001

South African National Department of Health, 2008, 'Results of the South African Demographic and Health Survey', viewed 02 February 2011, from http://www. doh.gov.za/facts/index.html

Stand Against Poverty, 2009, 'Day of the African Child: The unending plight of African children', viewed 02 February 2011, from http://www.standagainstpoverty.org/

Stata Corporation, 2010, User guide for STATA version 11, STATA Corporation, Houston, Texas, USA.

Statistics South Africa, 2003, 'Mortality and causes of death in South Africa 19972003', viewed 02 February 2011, from http://www.statssa.gov.za/

Statistics South Africa, 2007, 'Statistics South Africa Annual Report 2006/2007', viewed 02 February 2011, from http://www.statssa.gov.za/

UNAIDS, 2009, 'AIDS and global health', viewed 02 February 2011, from http://data. unaids.org/pub/Report/2009/aidsandglobalhealth_en.pdf

UNDP, 2009, 'Millennium development goals', viewed 02 February 2011, from http:// www.undp.org/mdg/basics.shtml

UNICEF, 2007, 'Causes of Child Mortality', viewed 05 October 2010, from http://www. unicef.org/progressforchildren/2007n6/index_41802.htm

UNICEF, 2009, 'The state of the world's children', viewed 02 February 2011, from http://www.unicef.org/sowc/index_47192.html

Union For African Population Studies, 2009, 'Child Mortality and Socioeconomic Status in Sub-Saharan Africa', viewed 02 February 2011, from http://www.uaps. org/journal/VOL $19 \mathrm{~N} 1 / 1$

United Nations Millennium Development Goals, 2007, 'Progress towards the Millennium Development Goals, 1990-2005', viewed 02 February 2011, from http://www.un.org/millenniumgoals/pdf/mdg2007.pdf

United Nations Statistics Division, 2009, 'Millennium development goals indicators', viewed 02 February 2011, from http://mdgs.un.org/unsd/mdg/Default.aspx

Winkley, M., Cubbin, C. \& Aim, D., 2006, 'Infant Mortality Trends and Differences between American Indian Native Infants and White Infants in the United States', American Journal of Public Health 96(12), 12-34.

World Bank, 2009, 'Report by the Independent Evaluations Group of the World Bank on development indicators', viewed 02 February 2011, from http://www. worldbank.org/ieg/

World Health Organization, 2005, 'Health-related Millennium Development Goals: Report by the Secretariat', viewed 02 February 2011, from http://whqlibdoc. who.int/publications/2005/9241562986.pdf

World Health Organization Statistical Information System, 2009, 'World health statistics report for 2009', viewed 02 February 2011, from http://www.who.int/ whosis/en/ 